ARTICLE

\title{
Rooting binder-free tin nanoarrays into copper substrate via tin-copper alloying for robust energy storage
}

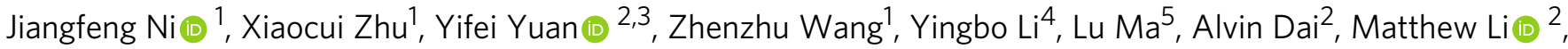
Tianpin Wu (i) ${ }^{5}$, Reza Shahbazian-Yassar (10 ${ }^{3}$, Jun Lu (i) ${ }^{2} \&$ Liang Li ${ }^{1 凶}$

The need for high-energy batteries has driven the development of binder-free electrode architectures. However, the weak bonding between the electrode particles and the current collector cannot withstand the severe volume change of active materials upon battery cycling, which largely limit the large-scale application of such electrodes. Using tin nanoarrays electrochemically deposited on copper substrate as an example, here we demonstrate a strategy of strengthening the connection between electrode and current collector by thermally alloying tin and copper at their interface. The locally formed tin-copper alloys are electron-conductive and meanwhile electrochemically inactive, working as an ideal "glue" robustly bridging tin and copper to survive harsh cycling conditions in sodium ion batteries. The working mechanism of the alloy "glue" is further characterized through a combination of electrochemical impedance spectroscopy, atomic structural analysis and in situ X-ray diffraction, presenting itself as a promising strategy for engineering binder-free electrode with endurable performance.

\footnotetext{
${ }^{1}$ School of Physical Science and Technology, Center for Energy Conversion Materials \& Physics (CECMP), Soochow University, 215006 Suzhou, P. R. China. ${ }^{2}$ Chemical Sciences and Engineering Division, Argonne National Laboratory, 9700 South Cass Avenue, Lemont, IL 60439, USA. ${ }^{3}$ Mechanical and Industrial Engineering Department, University of Illinois at Chicago, Chicago, IL 60607, USA. ${ }^{4}$ Key Laboratory of Advanced Ceramics and Machining Technology (Ministry of Education), School of Materials Science and Engineering, Tianjin University, 300072 Tianjin, China. ${ }^{5}$ Advanced Photon Sources, X-ray Science Division, Argonne National Laboratory, 9700 South Cass Avenue, Lemont, IL 60439, USA. ${ }^{凶}$ email: Il@suda.edu.cn
} 
tight and reliable bonding between electrode materials and current collectors is the prerequisite toward high-rate and endurable energy storage property in rechargeable ion batteries ${ }^{1}$. Most strategies addressing this issue involve the use of polymer-based binders, such as PVDF, which, although efficiently bond electrode particles with each other to the current collectors, severely decrease the energy density due to their electrochemical inactivity ${ }^{2}$. What's worse, the electron-insulating nature of binders cuts off the electron pathway among particles and thus degrades the rate performance of associated electrode materials.

As such, binder-free electrodes have been developed to push the energy density limit of active battery materials by increasing their ratio in the electrodes ${ }^{3}$. Some methods such as electrochemical deposition have been reported to successfully prepare binder-free electrode with the active materials tightly grown to the surface of current collector ${ }^{4,5}$. In spite of the achieved high energy density of these designs, the long-term cycling stability is significantly compromised due to the lack of efficient binding intermediates ${ }^{6}$. This situation is worsened for electrode materials experiencing intrinsic volume expansion and contraction during repetitive battery cycling, such as transitional metal oxide with a conversion-based energy storage mechanism and silicon (tin, germanium, etc.) with an alloying-based mechanism ${ }^{7}$.

For example, Sn, as a sodium ion battery anode, features a theoretical capacity of $847 \mathrm{mAh} \mathrm{g}^{-1}\left(\mathrm{Sn} \rightarrow \mathrm{Na}_{15} \mathrm{Sn}_{4}\right)$ with high electronic conductivity, low toxicity and low sodiation potential of $\sim 0.3 \mathrm{~V}$ (vs. $\mathrm{Na}^{+} / \mathrm{Na}$ ). However, the formation of $\mathrm{Na}_{15} \mathrm{Sn}_{4}$ alloy results in a huge volume expansion of $420 \%$, which leads to the generation of fractures and cracks inside Sn electrodes and continuous evolution of solid electrode/electrolyte interphase $(\mathrm{SEI})^{8}$. To mitigate these issues, several structural designs on $\mathrm{Sn}$ anodes have been established in recent years. One representative design involves the synthesis of composites of ultrafine Sn nanoparticles encapsulated in carbon matrix, which, however, only provides moderate specific capacity due to the presence of dense carbon ${ }^{9,10}$. Another approach refers to three-dimensional (3D) electrode architectures based on templates, for example, virus or wood $^{11,12}$. Architectured electrodes exhibit enhanced energy storage performance due to the unique structural characteristics of large accessible surface, free electrolyte permeation channel, additional space for volume change $e^{6,13,14}$. Specifically, nanowalls are particularly useful due to the shorter diffusion distance for $\mathrm{Na}$-ions to reach the core of the metal nanowalls. Furthermore, the space between nanowalls allows the free expansion of $\mathrm{Sn}$ electrodes to release stress and strain, thus minimizing the possibility of electrode failure. However, the key problem associated with deposited arrays of nano-sized dimensions is their adhesion to the substrate. Over cycling, the detachment of Sn electrode from the substrate/current collector is inevitable due to the continuous volume expansion/contraction, regardless of whether implementing binders or binder-free strategy.

Targeting $\mathrm{Sn}$ as an anode for sodium-ion batteries, we demonstrate here a strategy of strengthening the connection between the electrode $(\mathrm{Sn})$ and the current collector $(\mathrm{Cu})$ by thermally alloying $\mathrm{Sn}$ and $\mathrm{Cu}$ at their interface region. $\mathrm{Sn}$ nanowall-shaped arrays (SnNA) are first electrochemically deposited onto $\mathrm{Cu}$ substrate, which is then followed by a mild $\left(180^{\circ} \mathrm{C}\right)$ but key heat treatment step. The presence of electrochemically inactive $\mathrm{Sn}-\mathrm{Cu}$ alloy serves as a structural glue to guarantee the adhesion between SnNA and $\mathrm{Cu}$ substrate. More importantly, the gradient-like distribution of $\mathrm{Sn}-\mathrm{Cu}$ ensures no abrupt change in volume expansion/contraction during repetitive sodiation/desodiation cycles and therefore maintains the overall structural integrity over long cycles. When directly used as an electrode for sodium storage, SnNA exhibits a reversible capacity of $801 \mathrm{mAh} \mathrm{g}^{-1}$ at $0.2 \mathrm{C}$ (where $\mathrm{C}$ is referred to as the current for full charge or discharge of the theoretical capacity in $1 \mathrm{~h}$, i.e., $847 \mathrm{~mA} \mathrm{~g}^{-1}$ ), a rate capability of $610 \mathrm{mAh} \mathrm{g}^{-1}$ at $5 \mathrm{C}$, and a retention of $501 \mathrm{mAh} \mathrm{g}^{-1}$ at $5 \mathrm{C}$ after 300 cycles. Considering its remarkable electrochemical performance and simple fabrication with scale-up capability, SnNA tightly rooted into current collector via $\mathrm{Cu}-\mathrm{Sn}$ alloying mechanism might inspire future engineering of electrode structures foe endurable energy storage applications.

\section{Results}

Physical characteristics. Aligned Sn nanowalls were electrochemically grown on $\mathrm{Cu}$ substrate by a template-free deposition, followed by thermal annealing at $180^{\circ} \mathrm{C}$ for $2 \mathrm{~h}$ in $\mathrm{Ar}$ flow, as illustrated in Fig. 1a. Details of the fabrication can be found in Methods and Supplementary Information. Scanning electron microscopy (SEM) characterization reveals the deposited product as an architecture of interwoven nanowalls vertically grow onto $\mathrm{Cu}$ foil (Supplementary Fig. 1). No morphological change of Sn nanowall arrays is observed after thermal annealing at $180^{\circ} \mathrm{C}$ in Ar flow. The individual nanowall has a nanosheet structure, with a thickness of 50-100 nm and a height of about $2.6 \mu \mathrm{m}$ (Fig. 1b, c). We speculate that the growth of Sn nanowalls might be attributed to a glycol-directed assembly ${ }^{15}$. Firstly, glycol-coordinated $\mathrm{Sn}^{4+}$ ions will be reduced to metallic $\mathrm{Sn}$ driven by current. At the mediation of glycol, the cross growth of Sn species is restricted by the hydrocarbon periphery, while the growth of Sn nanosheets is then preferred (Supplementary Fig. 2). Without the mediation from glycol, only nanoparticles of Sn can be obtained (Supplementary Fig. 3). Interestingly, evident diffusion of $\mathrm{Cu}$ element into Sn matrix for alloying reaction is observed throughout the annealed nanowalls via elemental mapping analysis (Fig. $1 \mathrm{~d}-\mathrm{g}$ ). This is because $\mathrm{Cu}-\mathrm{Sn}$ alloy reaction proceeds significantly at temperatures above $100^{\circ} \mathrm{C}^{16}$. Since the alloying process is controlled by diffusion, the concentration profile of $\mathrm{Cu}$ in the $\mathrm{Sn}$ nano wall will naturally increase when one moves closer toward the $\mathrm{Cu}$ substrate, as reflected by Fig. 1d-g. This ensures a smooth gradient blend of $\mathrm{Sn}$ and $\mathrm{Cu}$ species at the alloying region, which is key to regulate the volume variation of Sn upon cycling. Scanning transmission electron microcopy (STEM) imaging further confirms the elemental distribution of $\mathrm{Cu}$ and $\mathrm{Sn}$ as well as their regional mixing state (Fig. $1 \mathrm{~h}-\mathrm{j}$ ). Atomic STEM-ABF images shown in Fig. 1k, 1 exhibit distinct crystalline patterns from two locations indicated by the white arrows. Compared to Fig. 11 showing pure $\mathrm{Sn}$ atomic columns, the $\mathrm{Sn}$ atomic columns in Fig. $1 \mathrm{k}$ are separated by extra atomic columns of lighter elements. Since $\mathrm{Cu}$ is much lighter than $\mathrm{Sn}$, such extra atoms are proposed to be $\mathrm{Cu}$ (note that STEM imaging contrast is associated with atomic weight) ${ }^{17,18}$. This is further confirmed by indexing the two atomic patterns in Fig. $1 \mathrm{k}, 1$ to standard phases of $\mathrm{Cu}_{6} \mathrm{Sn}_{5}$ alloy ${ }^{19}$ and tetragonal $\mathrm{Sn}^{20}$, respectively. The formation of alloy phases has also been corroborated by transmission electron microcopy (TEM) shown in Supplementary Fig. 4.

Ex-situ high-energy X-ray diffraction (XRD) patterns in Fig. 2a reveal the significant difference between SnNA samples with and without annealing treatment. The deposited Sn sample is well crystallized in a tetragonal phase (PDF \#04-0673). After a mild annealing at $180^{\circ} \mathrm{C}$, although tetragonal $\mathrm{Sn}$ remains the main phase, new phases related to orthorhombic $\mathrm{Cu}_{3} \mathrm{Sn}$ (PDF \#011240) and $\mathrm{Cu}_{6} \mathrm{Sn}_{5}$ (PDF \#02-0713) appear. The new phases are derived from the alloying process of $\mathrm{Sn}$ with $\mathrm{Cu}$, which has been facilitated by heating ${ }^{16}$. To explore the structural evolution and atomic arrangements of SnNA upon thermal annealing, we conducted X-ray absorption (XAS) measurement. We focus on the X-ray absorption fine structure (XAFS) at Sn K-edge, the corresponding Fourier transformation curves of which are 
a
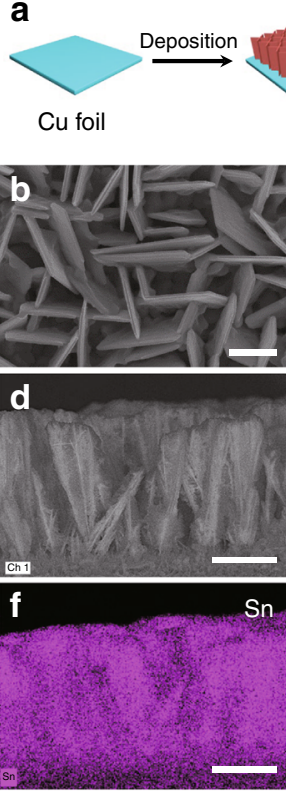

h

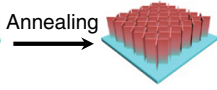

Sn nanowalls
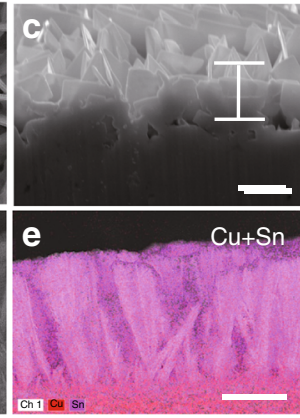

$\mathrm{Cu}$

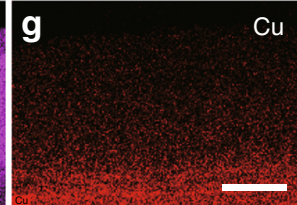

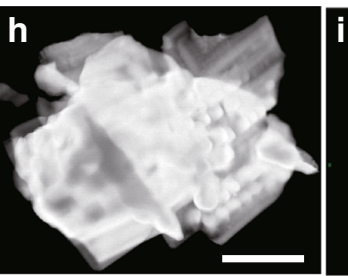
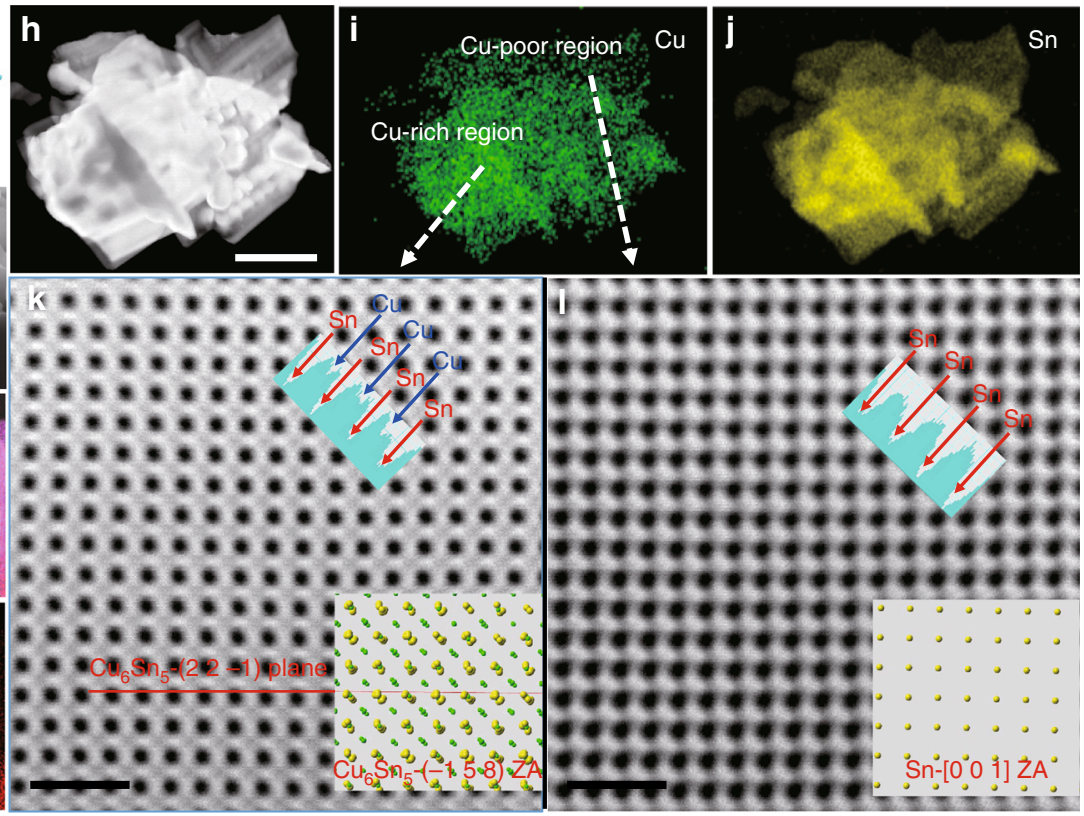

Fig. 1 Synthesis, morphology and structure analyses of SnNA. a Schematic illustration of electrochemical synthesis process. SEM images of $\mathbf{b}$ top view and $\mathbf{c}$ side view. $\mathbf{d}-\mathbf{g}$ Elemental mapping of energy dispersive X-ray spectroscopy reveals the diffusion of Cu throughout the nanowall. $\mathbf{e} \mathrm{Cu}$ and $\mathrm{Sn}, \mathbf{f} \mathrm{Sn}$, and $\mathbf{g} \mathrm{Cu}$. $\mathbf{h}$ Low-mag STEM-HAADF image of one SnNA. $\mathbf{i}, \mathbf{j}$ EDS mapping of Cu (green) and Sn (yellow). $\mathbf{k} \mathrm{STEM}-\mathrm{ABF}$ image of the $\mathrm{Cu}_{6} \mathrm{Sn}_{5}$ atomic structure viewed along the zone axis of [-15 8]. I STEM-ABF image of the Sn atomic structure viewed along the zone axis of [0 0 1]. $\mathbf{k}, \mathbf{I}$ The line profiles are given and compared in the insets to highlight the presence of $\mathrm{Cu}$ columns in $\mathrm{Cu}_{6} \mathrm{Sn}_{5}$. Atomic models matching each experimental observation are also given in the right bottom insets with yellow sphere for $\mathrm{Sn}$ and green sphere for $\mathrm{Cu}$. Scale bar: b $1 \mu \mathrm{m}, \mathbf{c}-\mathbf{g} 2 \mu \mathrm{m}, \mathbf{h} 1 \mu \mathrm{m}, \mathbf{k}, \mathbf{I} 1 \mathrm{~nm}$.
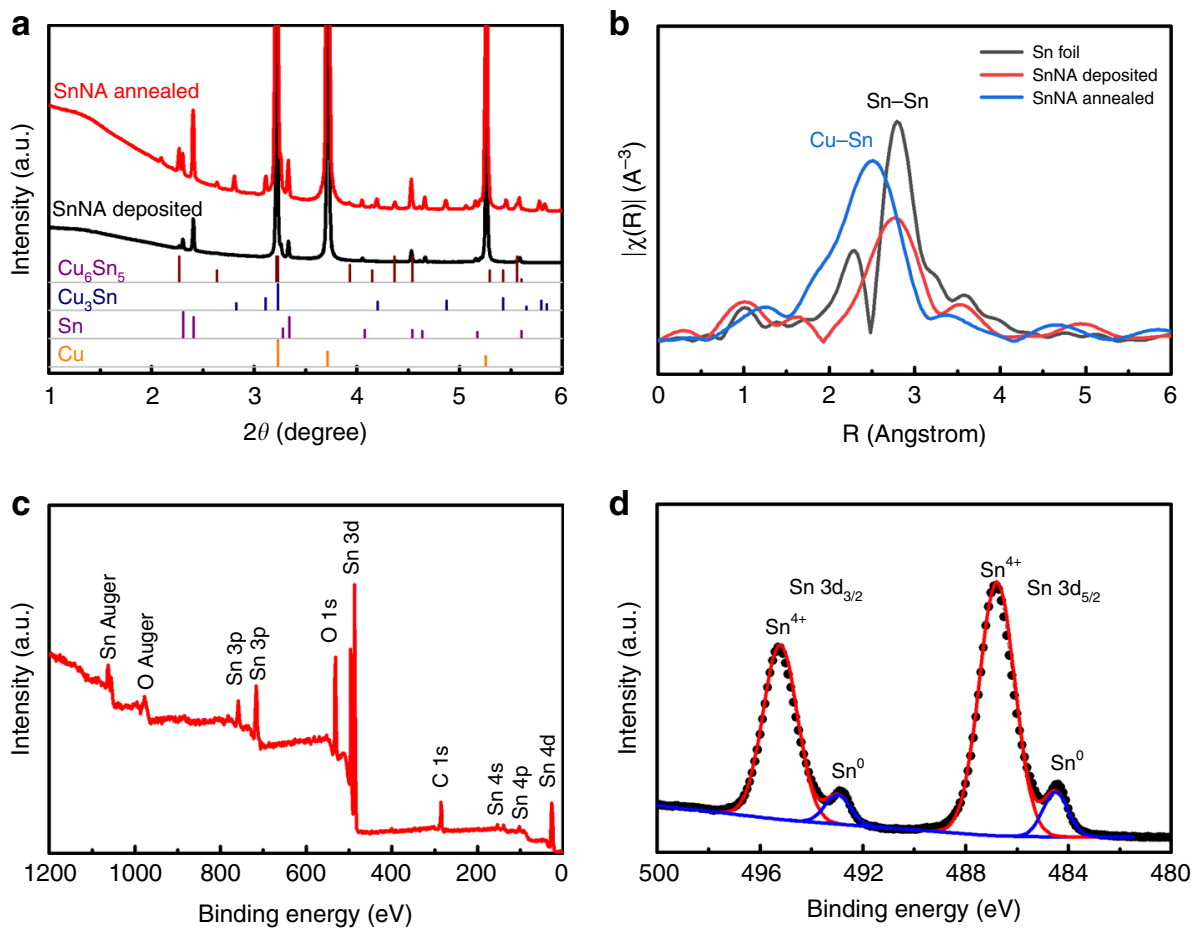

Fig. 2 Structural characterization of SnNA. a Ex-situ high-energy XRD patterns of as-deposited and annealed SnNA samples, showing the formation of alloy phases of $\mathrm{Cu}_{3} \mathrm{Sn}$ and $\mathrm{Cu}_{6} \mathrm{Sn}_{5}$ after thermal annealing at $180^{\circ} \mathrm{C}$. b Fourier transformation curves of XAFS for $\mathrm{Sn}$ edges. Sn foil is used as a reference. $\mathbf{c}$ XPS survey spectrum. $\mathbf{d}$ XPS core-level spectrum of Sn $3 d$, showing the presence of surface tin oxides.

depicted in Fig. 2b. The Fourier transformation spectrum of Sn foil exhibits one main peaks at $2.79 \AA$, corresponding to the $\mathrm{Sn}$-Sn coordination ${ }^{21}$. As-deposited SnNA shows a similar peak at a position of $2.76 \AA$, which shifts to a remarkably lower location of $2.52 \AA$ after thermal annealing. This lower-location peak suggests the prevailing existence of $\mathrm{Sn}-\mathrm{Cu}$ bonding in annealed SnNA, whose bond length is distinctly shorter than that of $\mathrm{Sn}-\mathrm{Sn}$ coordination ${ }^{22}$. This is in good agreement with the result of XRD, and further confirms the generation of alloy phase of $\mathrm{Cu}_{3} \mathrm{Sn}$ and $\mathrm{Cu}_{6} \mathrm{Sn}_{5}$ by mild annealing. 
No metal oxides such as $\mathrm{SnO}$ and $\mathrm{SnO}_{2}$ are detected according to the Raman scattering spectrum of the final SnNA product (Supplementary Fig. 5) ${ }^{23}$. However, by nature, a tin oxide layer would be formed upon exposure of $\mathrm{Sn}$ nanowalls to air. The presence of surface oxide layer could be probed by X-ray photoelectron spectroscopy (XPS, Fig. 2c). Notably, there is a C1s signal in the XPS survey spectrum, which is due to ubiquitous carbon contamination on samples during air exposure ${ }^{24}$. Figure 2d presents the core-level spectrum of $\mathrm{Sn} 3 \mathrm{~d}$ consisting of two peaks located at 495.2 and $486.7 \mathrm{eV}$, which can be assigned to $\mathrm{Sn}^{4+}$, and two another peaks at $492.8,484.3 \mathrm{eV}$ attributed to metallic $\mathrm{Sn}^{20}$. Despite a stronger signal of $\mathrm{Sn}^{4+}$ compared to $\mathrm{Sn}$, the content of tin oxides should be negligible as XPS is a surface technique with a penetration depth within several nanometers.

Electrochemical properties. To demonstrate the superiority of such unique architecture of SnNA, electrochemical sodium cointype cells were assembled and tested. A piece of annealed SnNA film was directly used as the working electrode, a $\mathrm{Na}$ foil as the counter electrode, and $1 \mathrm{M} \mathrm{NaPF}_{6}$ dissolved in diglyme as the electrolyte. Electrochemical behaviors of SnNA were examined by cyclic voltammetry (CV) and galvanostatic charge and discharge, as presented in Fig. 3. The initial $\mathrm{CV}$ curve at a scan rate of $0.2 \mathrm{mV} \mathrm{s}^{-1}$ shows an evident peak at $0.80 \mathrm{~V}$, which diminishes at
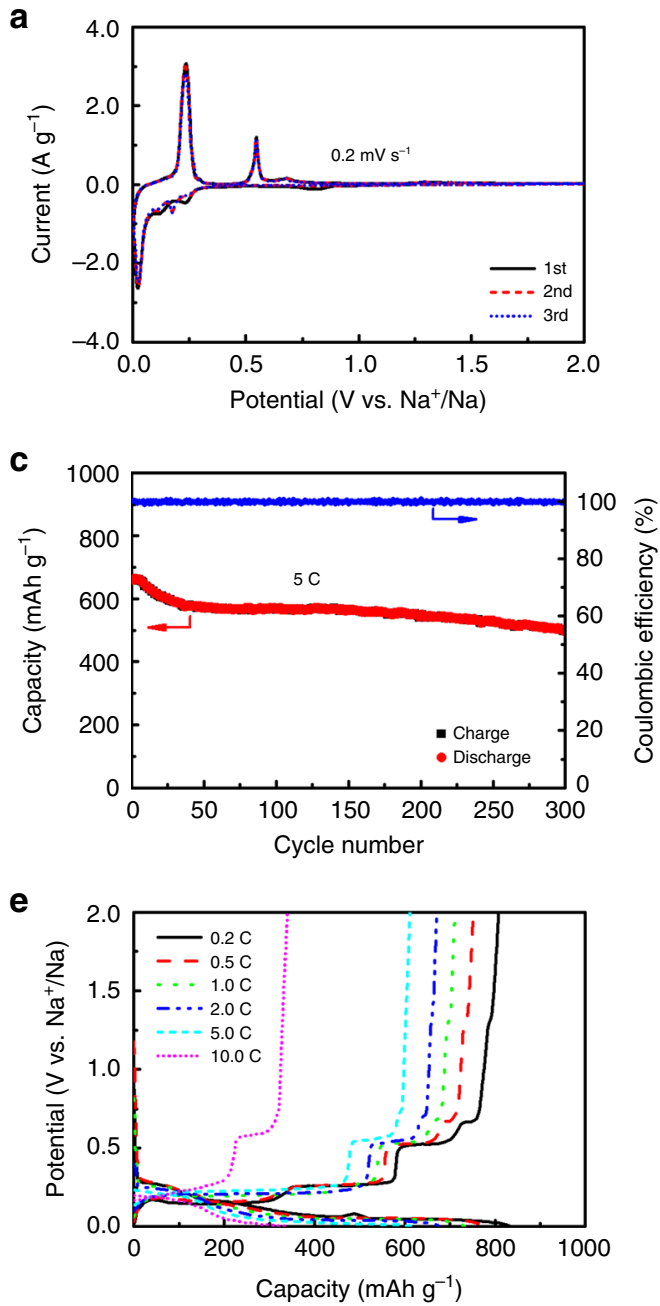

the following cycles, characteristic of the formation of SEI. Three redox peaks at $0.23,0.12$, and $0.03 \mathrm{~V}$ represent a stepwise alloying of $\mathrm{Sn}$ with $\mathrm{Na}$ to form $\mathrm{NaSn}, \mathrm{Na}_{9} \mathrm{Sn}_{4}$, and $\mathrm{Na}_{15} \mathrm{Sn}_{4}$, respectively ${ }^{25}$. The corresponding dealloying peaks occur at $0.24,0.55$, and $0.68 \mathrm{~V}$. The stepwise (de)alloying process is further confirmed by galvanostatic test at $0.2 \mathrm{C}$ (Fig. 3b). SnNA exhibits an initial sodiation capacity of $898 \mathrm{mAh}^{-1}$, out of which a capacity of $801 \mathrm{mAh} \mathrm{g}^{-1}$ is reversibly desodiated. The Coulombic efficiency $(89 \%)$ in the first cycle could be further enhanced to $92 \%$ by annealing SnNA in $\mathrm{Ar} / \mathrm{H}_{2}(v / v=95: 5)$ flow to eliminate trace oxides, which are less electrochemically reversible (Supplementary Fig. 6). Besides possessing a high capacity, SnNA also shows a stable cycling (Fig. 3c), retaining a desodiation capacity of $501 \mathrm{mAh} \mathrm{g}^{-1}$ (76\% of the initial value) over 300 cycles at a high rate of $5 \mathrm{C}$. In contrast, the electrodeposited product of Sn particles exhibit a much lower desodiation capacity of $567 \mathrm{mAh} \mathrm{g}^{-1}$ with a poor cycling stability (Supplementary Fig. 7). The SnNA electrode/electrolyte interphase is monitored by electrochemical impedance spectroscopy. The almost unchanged spectra of electrode upon 100 cycles (Supplementary Fig. 8) suggest that the nanoglue ( $\mathrm{Sn}-\mathrm{Cu}$ alloy) is indeed quite stable. Moreover, postmortem SEM and TEM images in Supplementary Fig. 9 confirms the conservation of nanowall structure after long-term cycles of $\mathrm{Na}$ reaction.

\section{b}

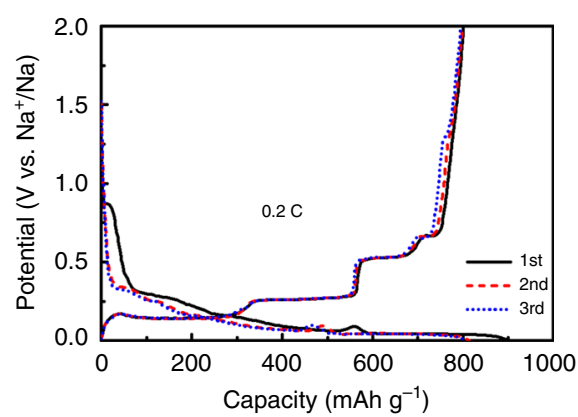

d

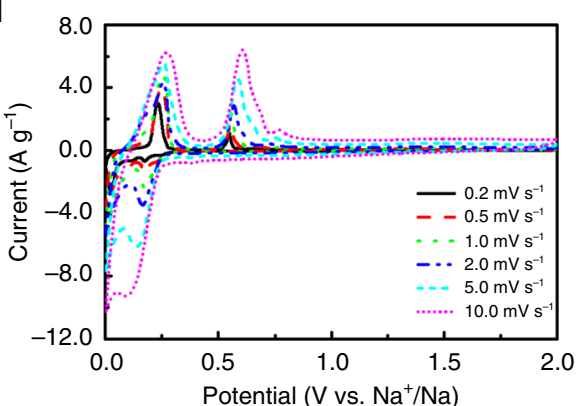

$f$

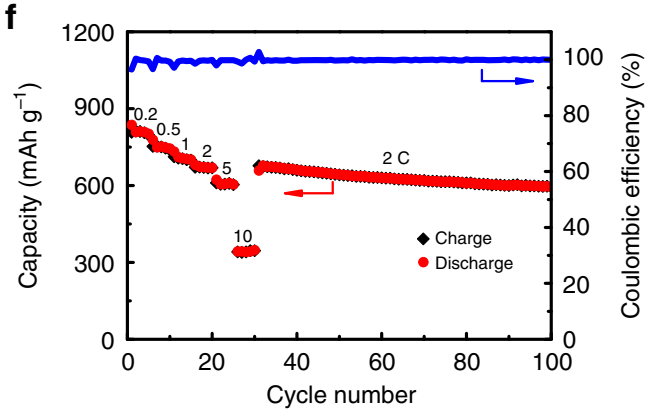

Fig. 3 Electrochemical sodium storage in SnNA. a CV curve at a sweep rate $0.2 \mathrm{mV} \mathrm{s}^{-1}$ for initial three cycles. b Galvanostatic curves at a rate of $0.2 \mathrm{C}$ during initial three cycles. c Cycling performance at a high charge-discharge rate of $5 \mathrm{C}$ for 300 cycles. The cell is initially activated at a low rate of $0.2 \mathrm{C}$ for 5 cycle. $\mathbf{d ~ C V}$ curves at various sweep rates ranging from 0.2 to $10 \mathrm{mV} \mathrm{s}^{-1}$. e Galvanostatic charge-discharge curves at current rates ranging from 0.2 to $10 \mathrm{C}$. $\mathbf{f}$ Rate cycling performance first at various current rates and then at a fixed rate of $2 \mathrm{C}$. 
a
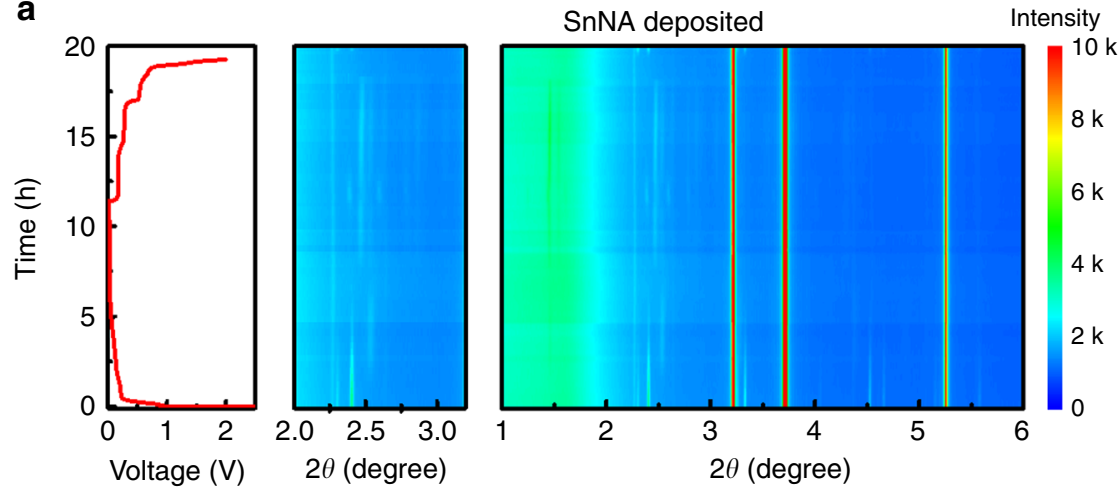

b
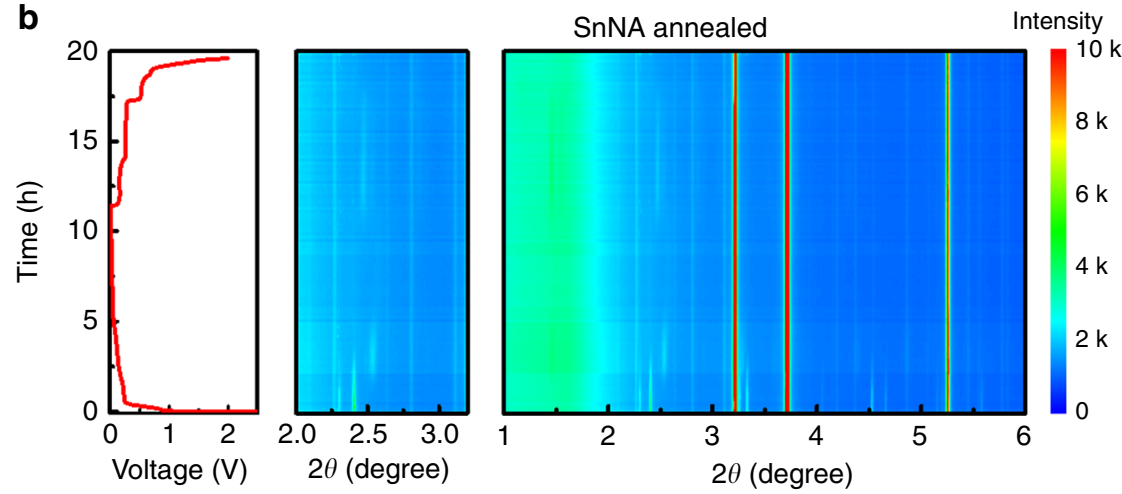

Fig. 4 Structure evolution of SnNA electrode in a working coin cell with Na metal as the counter revealed by in-situ XRD. a As-deposited SnNA, b Asannealed SnNA. a, $\mathbf{b}$ The left panel is the voltage profile of the electrode, while the right is the two-dimensional diffraction patterns collected in a transmission mode with an exposure time of $60 \mathrm{~s}$. Intermediate crystalline phases of $\mathrm{Na}_{9} \mathrm{Sn}_{4}$ (peaks at 1.462 and $2.530^{\circ}$ ) and $\mathrm{Na}_{15} \mathrm{Sn}_{4}($ peaks at 2.392 and $2.602^{\circ}$ ) are clearly observed for sodiated $\mathrm{SnNA}$ electrodes. The middle panel is a zoomed pattern where $\mathrm{Cu}_{3} \mathrm{Sn}$ and $\mathrm{Cu}_{6} \mathrm{Sn}_{5}$ alloy phases remain intact upon (de)sodiation.

Kinetic characters of SnNA were explored further by $\mathrm{CV}$ at various sweep rates ranging from 0.2 to $20.0 \mathrm{mV} \mathrm{s}^{-1}$ (Fig. $3 \mathrm{~d}$ and Supplementary Fig. 10). Impressively, the CV curve well maintains the shape and position of redox peaks at each sweep rate, signifying a robust kinetic behavior. Similarly, galvanostatic curves shows a vigorous charge-discharge rate capability (Fig. 3e). SnNA affords desodiation capacities 807, 752, 712, 671, and 610 $\mathrm{mAh} \mathrm{g}^{-1}$ at rates of $0.2,0.5,1,2$, and $5 \mathrm{C}$, respectively. Even at a much higher rate of $10 \mathrm{C}$, it still affords a reversible capacity of $341 \mathrm{mAh} \mathrm{g}^{-1}$. Despite a decrease in capacity upon increasing rates, the potential plateaus and the small polarization are well preserved. High-rate stability and reversibility are further corroborated in Fig. 3f. Such a 3D SnNA electrode is superior

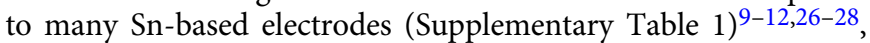
unambiguously proving the efficacy of our electrode design.

Mechanism analysis. As shown previously in our microscopy and post-cycling EIS studies, it is clear that there are no apparent changes in both the morphology and electron/ionic conduction pathways. To track the structural evolution during cycling, in situ high-energy XRD experiments were conducted. Figure 4a, b show the two-dimensional contour plots for the local structural and phase evolution of both deposited and annealed SnNA electrodes during the 1 st galvanostatic cycle at $0.1 \mathrm{C}$, where red color represents high intensity while blue color stands for low intensity. As expected, at the beginning of sodiation, the diffraction peaks of $\mathrm{Sn}$ gradually weaken, while an intermediate phase of $\mathrm{Na}_{9} \mathrm{Sn}_{4}$ (PDF \#31-1326) with characteristic peaks at $1.462^{\circ}$ and $2.530^{\circ}$ appears for both samples. Upon the further sodiation, these peaks gradually decrease in intensity, and in particular the peak at $2.530^{\circ}$ shifts negatively to $2.465^{\circ}$. Concurrently, new diffraction peaks at $1.447^{\circ}, 1.608^{\circ}, 2.392^{\circ}$, and $2.602^{\circ}$ characteristic of crystalline $\mathrm{Na}_{15} \mathrm{Sn}_{4}$ (PDF \#31-1327) tardily appears, indicating a further alloying process. At the final discharge state of $1 \mathrm{mV}$, the characteristic peaks of $\mathrm{Na}_{9} \mathrm{Sn}_{4}$ and $\mathrm{Na}_{15} \mathrm{Sn}_{4}$ remain visible, suggesting a co-existence between the different phases ${ }^{29}$. Additionally, the peaks corresponding to $\mathrm{Na}_{9} \mathrm{Sn}_{4}$ and $\mathrm{Na}_{15} \mathrm{Sn}_{4}$ disappeared while the Sn XRD peaks could return to their original position once charged back to $2 \mathrm{~V}$, indicating that the (de)sodiation process is highly reversible. It is worth mentioning that the peaks due to phases of $\mathrm{Cu}_{6} \mathrm{Sn}_{5}$ and $\mathrm{Cu}_{3} \mathrm{Sn}$ derived from annealing remain intact upon sodium cycling, suggesting that the formation of $\mathrm{Na}-\mathrm{Cu}-\mathrm{Sn}$ alloy is electrochemically unfavorable. Recent studies reveal that $\mathrm{Cu}-\mathrm{Sn}$ alloys exhibit a much lower activity toward sodium than lithium, and their sodiation process is quite similar to that of the pure $\mathrm{Sn}^{30}$. This unusual behavior suggests the sodiation activity might come from the aggregation of $\mathrm{Sn}$ rather than the other part of $\mathrm{Cu}-\mathrm{Sn}$ alloys. This means that these nanoglue phases are electrochemically inert and not prone to stresses experienced from the sodiation/desodiation process ${ }^{31}$, which can further prevent electrode cracks or any material disconnections with the current collector caused by volume variation of Sn. Following this observation, it is clear that the volume expansion of the $\mathrm{Cu}-\mathrm{Sn}$ alloy/Sn blends will depend on their composition. We believe, due to the concentration gradient produced from a diffusion-based $\mathrm{Cu}-\mathrm{Sn}$ alloying process, the volume expansive stress also decreases in a smooth manner (nonabrupt) as one moves from the pure Sn nanowalls toward the pure $\mathrm{Cu}$ substrate. This concentration gradient profile has been verified by the XPS spectra collected at different etching depths 

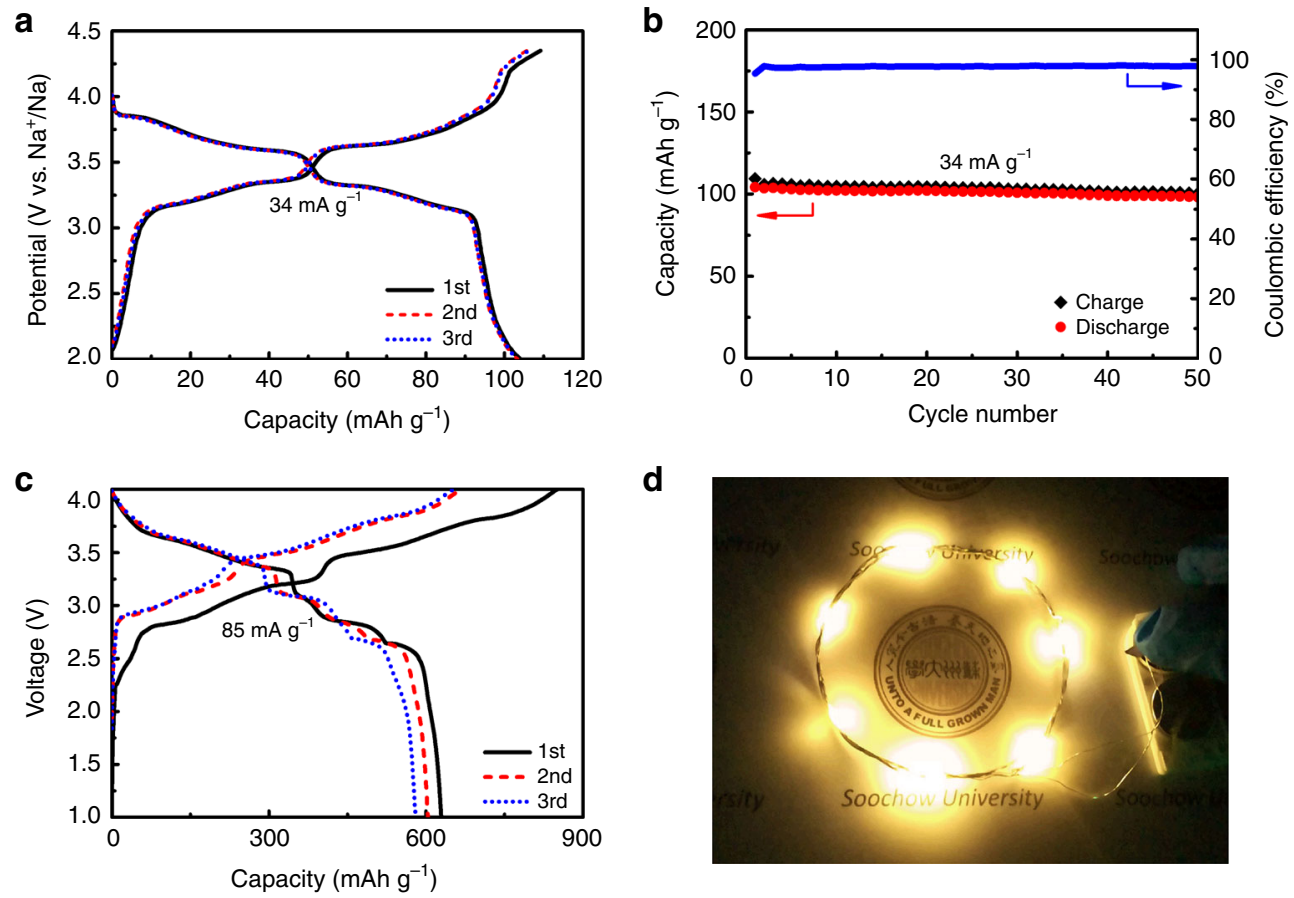

Fig. 5 Electrochemical performance of $\mathbf{S n N A} / / \mathbf{N a}_{\mathbf{0 . 6 7}}\left(\mathbf{N i}_{\mathbf{0 . 2 3}} \mathbf{M g}_{\mathbf{0 . 1}} \mathbf{M n}_{\mathbf{0 . 6 7}}\right) \mathbf{O}_{\mathbf{2}}$ full cell. a, b Electrochemical performance of $\mathrm{Na}_{0.67}\left(\mathrm{Ni}_{0.23} \mathrm{Mg}_{0.1} \mathrm{Mn}_{0.67}\right) \mathrm{O}_{2}$ cathode, a galvanostatic charge-discharge curves and $\mathbf{b}$ cycling performance at a rate of $34 \mathrm{~mA} \mathrm{~g}^{-1}$. c Galvanostatic curves of SnNA// $\mathrm{Na}_{0.67}\left(\mathrm{Ni}_{0.23} \mathrm{Mg}_{0.1} \mathrm{Mn}_{0.67}\right) \mathrm{O}_{2}$ full cell at a rate of $85 \mathrm{~mA} \mathrm{~g}^{-1}$. The capacity is calculated based on the mass of SnNA anode. $\mathbf{d}$ Photograph shows two charged cells in series lighting up LED arrays.

(durations) by $\mathrm{Ar}^{+}$ion, as shown in Supplementary Fig. 11, where the content of $\mathrm{Cu}$ continuously increases from the top $\mathrm{Sn}$ to the bottom substrate. As Supplementary Fig. 12 shows, SnNA without thermal annealing only retains $326 \mathrm{mAh} \mathrm{g}^{-1}$, or $70 \%$ of its initial value over 100 cycles at $2 \mathrm{C}$, which is much inferior to the annealed counterpart.

In light of its remarkable electrochemical activity and durability enabled by the unique 3D architecture, we evaluate the potential of SnNA electrodes in practical reality by assembling full cells of SnNA// $/ \mathrm{Na}_{0.67}\left(\mathrm{Ni}_{0.23} \mathrm{Mg}_{0.1} \mathrm{Mn}_{0.67}\right) \mathrm{O}_{2}$. To minimize irreversible capacity loss, the mass ratio between anode and cathode is carefully adjusted to 1:8. The $\mathrm{Na}_{0.67}\left(\mathrm{Ni}_{0.23} \mathrm{Mg}_{0.1} \mathrm{Mn}_{0.67}\right) \mathrm{O}_{2}$ cathode was prepared via a sol-gel approach ${ }^{32}$, followed by a conventional doctor-blade technique. Details of materials and battery assembly can be found in Methods section. As Fig. 5a, b shows, the $\mathrm{Na}_{0.67}\left(\mathrm{Ni}_{0.23} \mathrm{Mg}_{0.1} \mathrm{Mn}_{0.67}\right) \mathrm{O}_{2}$ cathode affords a reversible capacity of $\sim 104 \mathrm{mAh} \mathrm{g}^{-1}$ at $34 \mathrm{~mA} \mathrm{~g}^{-1}$ with favorable cycling stability. The full cell of $\mathrm{SnNA} / / \mathrm{Na}_{0.67}\left(\mathrm{Ni}_{0.23} \mathrm{Mg}_{0.1} \mathrm{Mn}_{0.67}\right) \mathrm{O}_{2}$ exhibits a reversible capacity of $629 \mathrm{mAh} \mathrm{g}^{-1}$ (based on the anode mass) in the voltage range of $4.1-1.0 \mathrm{~V}$. The average working voltage is $\sim 3.2 \mathrm{~V}$, and the specific energy is calculated to be $199 \mathrm{Wh} \mathrm{kg}^{-1}$ based on the mass of active materials. When fully charged, the cell works well in lighting up LED arrays, thereby demonstrating its potential in practical energy application for electronics.

\section{Discussion}

We have demonstrated the template-free construction of 3D Sn nanowall arrays tightly rooted into $\mathrm{Cu}$ substrate via $\mathrm{Sn}-\mathrm{Cu}$ alloying reactions. Our unique mild annealing step, following the $\mathrm{Sn}$ electrodeposition onto $\mathrm{Cu}$, led to the formation of $\mathrm{Cu}-\mathrm{Sn}$ alloy phases, which serves as an adhesive or so-called "nanoglue" between the SnNA and $\mathrm{Cu}$ substrate. This nanoglue prevented the disconnection of the SnNA from the $\mathrm{Cu}$ substrate over cycles of sodium ion batteries. Our anode design delivered a high reversible capacity of 801 and $610 \mathrm{mAhg}^{-1}$ at 0.2 and $5 \mathrm{C}$, respectively. Furthermore, we have developed full cells of SnNA// $\mathrm{Na}_{0.67}\left(\mathrm{Ni}_{0.23} \mathrm{Mg}_{0.1} \mathrm{Mn}_{0.67}\right) \mathrm{O}_{2}$ capable of affording a working voltage of $\sim 3.2 \mathrm{~V}$ and a specific energy of $199 \mathrm{mWh} \mathrm{g}^{-1}$ (on the basis of active materials). The strategy of developing and consolidating $3 \mathrm{D}$ binder-free electrodes is applicable to other alloy-based and conversion-based electrodes that have been plagued by the notorious cycling-induced volume variation, and hence may pave the way for the development of high-capacity and high-rate anodes in various rechargeable battery systems.

\section{Methods}

Synthesize of SnNA. Sn nanowall array was directly deposition on $\mathrm{Cu}$ foil $(0.1 \mathrm{~mm}$, $99.95 \%)$ in a glycol/ $\mathrm{H}_{2} \mathrm{O}$ (1:1 by volume) electrolyte consisting of $0.06 \mathrm{M} \mathrm{SnCl}_{4}$ and $0.12 \mathrm{M}$ trisodium citrate. The electrodeposition employs a three-electrode set-up with a piece of $\mathrm{Cu}$ foil as the working electrode, a platinum gauze as the counter electrode, and $\mathrm{ag} / \mathrm{AgCl}$ as the reference electrode. The electrodeposition was carried out at a current of $0.01 \mathrm{~A} \mathrm{~cm}^{-2}$ for $1200 \mathrm{~s}$ with a constant stirring of 100 rotations $\mathrm{min}^{-1}$ at ambient temperature $\left(\sim 25^{\circ} \mathrm{C}\right)$. Prior to deposition, $\mathrm{Cu}$ substrates were ultrasonically cleaned in ethanol, diluted acetic acid and ethanol successively. One side of $\mathrm{Cu}$ foil is covered by scotch tape to ensure the deposition only occurring in the other side. The deposited Sn nanowall array was rinsed with water and ethanol, dried at $100{ }^{\circ} \mathrm{C}$ in vacuum, and finally annealed in Ar flow at $180^{\circ} \mathrm{C}$ for $2 \mathrm{~h}$. The mass of SnNA was estimated to be $0.6 \mathrm{mg} \mathrm{cm}^{-2}$ by measuring the weight difference before and after deposition. By contrast, $\mathrm{Sn}$ thin film rather than nanowall was deposition in aqueous electrolyte of $0.1 \mathrm{M} \mathrm{SnCl}_{4}$ without glycol.

Characterization. Morphology of SnNA samples were characterized by SEM (Hitachi SU-8010) and TEM (FEI Tecnai G2 T20). The structure of SnNA samples was characterized by a Rigaku D/MAX-2000PC XRD diffractometer and a HORIBA Jobin Yvon LabRAM HR800 Raman spectroscopy. Chemical composition of samples was analyzed by XPS (Thermo Fisher Scientific Escalab 250Xi). An Al anode running at $250 \mathrm{~W}$ was used as the X-ray source and the base pressure in the analytic chamber about $5 \times 10^{-9}$ Torr. The atomic imaging is done using an aberration-corrected STEM (JEOL ARM200CF) operated at $200 \mathrm{kV}$.

X-ray absorption spectroscopy (XAS) measurements. Ex-situ of XAS of the asprepared SnNA without and with thermal annealing electrodes were measured at 20-BM-B of APS at Argonne National Laboratory in transmission mode with electron energy of $7 \mathrm{GeV}$. Sn K-edge spectra were collected and processed by Athena software. 
Ex-situ and in-situ high-energy X-ray diffraction (XRD) measurements. Exsitu and in-situ XRD of the as-prepared SnNA electrodes without and with thermal annealing were measured at 11-ID-C of the Advanced Photo Source at Argonne National Laboratory with a wavelength of $0.1173 \AA$ A. Two-dimensional diffraction patterns were collected in a transmission mode with an exposure time of $60 \mathrm{~s}$. A standard sample of $\mathrm{CeO}_{2}$ was applied to calibrate the 2D diffraction patterns, which can be converted to one-dimensional patterns using Fit 2D software. For the in-situ XRD experiments, home-made coin cells and $\mathrm{Na}$ foil anode with $3 \mathrm{~mm}$ holes were used to allow beam pass through. The holes at the both sides of cases of coin cell were sealed with Kapton tape before cell assembly. During the in situ XRD study, the cells were discharged and charged at a constant rate of 0.1 or $0.2 \mathrm{C}$ between $1 \mathrm{mV}$ and $2 \mathrm{~V}$ via a MACCOR cycler. $2 \mathrm{D}$ diffraction patterns were recorded around every $600 \mathrm{~s}$, which could capture the structural and phase evolution during the 1 st cycle of cell.

Electrochemical tests. The electrochemical evaluation was performed on 2032-type coin cells assembled in an Ar-filled Mikrouna glove box. The half-cell consists of a SnNA working electrode and a $\mathrm{Na}$ foil counter electrode. Galvanostatic tests of the cells were operated on a Land CT2001A battery test system. Cyclic voltammetry and electrochemical impedance spectroscopy were performed on an Autolab electrochemical workstation. All electrochemical tests were performed at room temperature $\left(\sim 25^{\circ} \mathrm{C}\right)$. To assemble full cells, $\mathrm{Na}_{0.67}\left(\mathrm{Ni}_{0.23} \mathrm{Mg}_{0.1} \mathrm{Mn}_{0.67}\right) \mathrm{O}_{2}$ cathode material was used. The $\mathrm{Na}_{0.67}\left(\mathrm{Ni}_{0.23} \mathrm{Mg}_{0.1} \mathrm{Mn}_{0.67}\right) \mathrm{O}_{2}$ material was synthesized by a sol-gel route. $\mathrm{A}$ mixed aqueous solution of sodium, nickel, magnesium and manganese and citric acid in a stoichiometric ratio was bathed at $60^{\circ} \mathrm{C}$ under continuous stirring until most water was evaporated. The resulting gel was then decomposed at $400{ }^{\circ} \mathrm{C}$ and finally annealed at $900^{\circ} \mathrm{C}$ for $15 \mathrm{~h}$ in air. To make cathode slurry, $80 \%$ of cathode material, $5 \%$ carbon black, $5 \%$ carbon nanotube, and $10 \%$ polyvinylidene fluoride were homogeneously mixed and cast onto an $\mathrm{Al}$ foil. The electrode sheet was cut into disks with a diameter of $12 \mathrm{~mm}$. The electrolyte is $1 \mathrm{M} \mathrm{NaPF}_{6}$ dissolved in diglyme.

\section{Data availability}

The data that support the findings of this study are available from the corresponding author upon reasonable request.

Received: 20 October 2019; Accepted: 12 February 2020;

Published online: 05 March 2020

\section{References}

1. Goodenough, J. B. How we made the Li-ion rechargeable battery. Nat. Electron 1, 204-204 (2018).

2. Kovalenko, I. et al. A major constituent of brown algae for use in high-capacity Li-ion batteries. Science 334, 75-79 (2011)

3. Sun, H. et al. Hierarchical 3D electrodes for electrochemical energy storage. Nat. Rev. Mater. 4, 45-60 (2019).

4. Liang, L. et al. Large-scale highly ordered Sb nanorod array anodes with high capacity and rate capability for sodium-ion batteries. Energy Environ. Sci. 8, 2954-2962 (2015).

5. Yue, C. et al. High performance 3D Si/Ge nanorods array anode buffered by TiN/ Ti interlayer for sodium-ion batteries. Adv. Funct. Mater. 25, 1386-1392 (2015).

6. Tan, G. et al. Freestanding three-dimensional core-shell nanoarrays for lithium-ion battery anodes. Nat. Commun. 7, 11774 (2016)

7. Li, L. et al. Recent progress on sodium ion batteries: potential high performance anodes. Energy Environ. Sci. 11, 2310-2340 (2018).

8. Li, Z., Ding, J. \& Mitlin, D. Tin and tin compounds for sodium ion battery anodes: phase transformations and performance. Acc. Chem. Res. 48, 1657-1665 (2015).

9. Liu, Y., Zhang, N., Jiao, L., Tao, Z. \& Chen, J. Ultrasmall Sn nanoparticles embedded in carbon as high-performance anode for sodium-ion batteries. Adv. Funct. Mater. 25, 214-220 (2015).

10. Mao, M. et al. Pipe-wire $\mathrm{TiO}_{2}-\mathrm{Sn} @$ carbon nanofibers paper anodes for lithium and sodium ion batteries. Nano Lett. 17, 3830-3836 (2017).

11. Liu, Y. et al. Tin-coated viral nanoforests as sodium-ion battery anodes. ACS Nano 7, 3627-3634 (2013).

12. Zhu, H. et al. Tin anode for sodium-ion batteries using natural wood fiber as a mechanical buffer and electrolyte reservoir. Nano Lett. 13, 3093-3100 (2013).

13. Ni, J. \& Li, L. Self-supported 3D array electrodes for sodium microbatteries. Adv. Funct. Mater. 28, 1704880 (2018).

14. Lukatskaya, M. R., Dunn, B. \& Gogotsi, Y. Multidimensional materials and device architectures for future hybrid energy storage. Nat. Commun. 7, 12647 (2016).

15. Liu, S. et al. Nanosheet-constructed porous $\mathrm{TiO}_{2}-\mathrm{B}$ for advanced lithium ion batteries. Adv. Mater. 24, 3201-3204 (2012).
16. Tu, K. N. Irreversible processes of spontaneous whisker growth in bimetallic Cu-Sn thin-film reactions. Phys. Rev. B 49, 2030-2034 (1994).

17. Yuan, Y., Amine, K., Lu, J. \& Shahbazian-Yassar, R. Understanding materials challenges for rechargeable ion batteries with in situ transmission electron microscopy. Nat. Commun. 8, 15806 (2017)

18. Yuan, Y. et al. Asynchronous crystal cell expansion during lithiation of $\mathrm{K}+$ stabilized $\alpha-\mathrm{MnO}_{2}$. Nano Lett. 15, 2998-3007 (2015).

19. Tan, X. F. et al. Characterisation of lithium-ion battery anodes fabricated via in-situ $\mathrm{Cu}_{6} \mathrm{Sn}_{5}$ growth on a copper current collector. J. Power Sources 415 50-61 (2019)

20. Nam, D.-H., Kim, T.-H., Hong, K.-S. \& Kwon, H.-S. Template-free electrochemical synthesis of Sn nanofibers as high-performance anode materials for Na-ion batteries. ACS Nano 8, 11824-11835 (2014).

21. Noh, M. et al. Monomer-capped tin metal nanoparticles for anode materials in lithium secondary batteries. Chem. Mater. 17, 3320-3324 (2005)

22. Fürtauer, S., Effenberger, H. S. \& Flandorfer, H. $\mathrm{CuLi}_{2} \mathrm{Sn}$ and $\mathrm{Cu}_{2} \mathrm{LiSn}$ : characterization by single crystal XRD and structural discussion towards new anode materials for Li-ion batteries. J. Solid State Chem. 220, 198-205 (2014)

23. Zheng, Y. et al. Boosted charge transfer in $\mathrm{SnS} / \mathrm{SnO}_{2}$ heterostructures: toward high rate capability for sodium-ion batteries. Angew. Chem. 128, 3469-3474 (2016).

24. Greczynski, G. \& Hultman, L. C 1s peak of adventitious carbon aligns to the vacuum level: dire consequences for material's bonding assignment by photoelectron spectroscopy. ChemPhysChem 18, 1507-1512 (2017).

25. Komaba, S. et al. Redox reaction of Sn-polyacrylate electrodes in aprotic $\mathrm{Na}$ cell. Electrochem. Commun. 21, 65-68 (2012).

26. Ruan, B. et al. Carbon-encapsulated Sn@N-doped carbon nanotubes as anode materials for application in SIBs. ACS Appl. Mater. Interfaces 9, 37682-37693 (2017).

27. Luo, B., Qiu, T., Ye, D., Wang, L. \& Zhi, L. Tin nanoparticles encapsulated in graphene backboned carbonaceous foams as high-performance anodes for lithium-ion and sodium-ion storage. Nano Energy 22, 232-240 (2016).

28. Liu, Y., Zhang, N., Jiao, L. \& Chen, J. Tin nanodots encapsulated in porous nitrogen-doped carbon nanofibers as a free-standing anode for advanced sodium-ion batteries. Adv. Mater. 11, 6702-6707 (2015)

29. Wang, J. W., Liu, X. H., Mao, S. X. \& Huang, J. Y. Microstructural evolution of tin nanoparticles during in situ sodium insertion and extraction. Nano Lett. 12, 5897-5902 (2012)

30. Thorne, J. S., Dunlap, R. A. \& Obrovac, M. N. $\left.\mathrm{Cu}_{6} \mathrm{Sn}_{5}\right)_{1-x} \mathrm{C}_{\mathrm{x}}$ active/inactive nanocomposite negative electrodes for $\mathrm{Na}$-ion batteries. Electrochim. Acta 112, 133-137 (2013).

31. Han, X. et al. Atomic-layer-deposition oxide nanoglue for sodium ion batteries. Nano Lett. 14, 139-147 (2013)

32. Wang, P. F. et al. Suppressing the P2-O2 phase transition of $\mathrm{Na}_{0.67} \mathrm{Mn}_{0.67} \mathrm{Ni}_{0.33} \mathrm{O}_{2}$ by magnesium substitution for improved sodium-ion batteries. Angew. Chem. Int. Ed. 55, 7445-7449 (2016).

\section{Acknowledgements}

The authors acknowledge the financial support of the National Natural Science Foundation of China (Grant Nos. 51872192, 51672182, 51772197), the Thousand Young Talents Plan, the Jiangsu Natural Science Foundation (Grant No. BK20180002), the Key University Science Research Project of Jiangsu Province (Grant No. 19KJA170001, 17KJA430013), the 333 High-Level Talents Project in Jiangsu Province, the Six Talent Peaks Project in Jiangsu Province, and of the Priority Academic Program Development (PAPD) of Jiangsu Higher Education Institutions. Work at Argonne National Laboratory was supported by the U. S. Department of Energy (DOE), Office of Energy Efficiency and Renewable Energy, Vehicle Technologies Office. Argonne National Laboratory is operated for DOE Office of Science by UChicago Argonne, LLC, under contract number DEAC02-06CH11357. Use of the Advanced Photon Source (APS) [beamlines 9-BM and 11ID-C], Office of Science user facilities, was supported by the U. S. Department of Energy, Office of Science, Office of Basic Energy Sciences, under Contract No. DE-AC0206CH11357. R. Shahbazian-Yassar and Y. Yuan acknowledge the financial support from NSF DMR-1809439. This work made use of instruments in the Electron Microscopy Service (Research Resources Center, UIC)

\section{Author contributions}

J.N., L.L., and J.L. conceived the idea and designed the experiments. J.N., X.Z., Y.Y., R.S.Y., and Z.W. conducted the synthesis, carried out the characterization and analyzed the results. A.D. Y.L., M.L. L.M., and T.W. carried out the high-energy XAS and XRD experiments. J.N., X.Z., Y.Y., A.D., M.L., and J.L. co-wrote the paper. All authors discussed the experiments and final manuscript. J.N., X.Z., and Y.Y. contributed equally.

\section{Competing interests}

The authors declare no competing interests. 


\section{Additional information}

Supplementary information is available for this paper at https://doi.org/10.1038/s41467020-15045-x

Correspondence and requests for materials should be addressed to L.L.

Peer review information Nature Communications thanks Liqiang Mai and the other, anonymous, reviewer(s) for their contribution to the peer review of this work.

Reprints and permission information is available at http://www.nature.com/reprints

Publisher's note Springer Nature remains neutral with regard to jurisdictional claims in published maps and institutional affiliations. (c) Open Access This article is licensed under a Creative Commons Attribution 4.0 International License, which permits use, sharing, adaptation, distribution and reproduction in any medium or format, as long as you give appropriate credit to the original author(s) and the source, provide a link to the Creative Commons license, and indicate if changes were made. The images or other third party material in this article are included in the article's Creative Commons license, unless indicated otherwise in a credit line to the material. If material is not included in the article's Creative Commons license and your intended use is not permitted by statutory regulation or exceeds the permitted use, you will need to obtain permission directly from the copyright holder. To view a copy of this license, visit http://creativecommons.org/licenses/by/4.0/.

(C) The Author(s) 2020 